\title{
PENGARUH JENIS DAN TINGKAT KERAPATAN GULMA TERHADAP PERTUMBUHAN AWAL TANAMAN UBIKAYU (Manihot esculenta Crantz) KLON UJ-5 (Kasetsart)
}

\author{
Deasy Maya Sari, Dad R.J. Sembodo \& Kuswanta F. Hidayat \\ Jurusan Agroteknologi, Fakultas Pertanian, Universitas Lampung \\ Jl. Prof. Soemantri Brojonegoro, No. 1 Bandar Lampung 35145 \\ Email : Deasymayasariecigo@gmail.com
}

\begin{abstract}
ABSTRAK
Penelitian ini bertujuan untuk mengetahui pengaruh jenis gulma terhadap pertumbuhan awal tanaman ubikayu, pengaruh kerapatan gulma terhadap pertumbuhan awal tanaman ubikayu, dan pengaruh interaksi antara jenis dan kerapatan gulma terhadap pertumbuhan awal tanaman ubikayu. Penelitian ini dilaksanakan di Lampung Selatan dan Laboratorium Gulma Universitas Lampung pada bulan Maret hingga Juni 2015. Perlakuan disusun secara faktorial dalam Rancangan Petak Berjalur dengan 3 kali ulangan. Faktor pertama adalah 3 jenis gulma yaitu, Asystasia gangetica, Cyperus rotundus dan Rottboelia exaltata dan faktor kedua adalah kerapatan 0, 10, 20, 40, dan $80 \mathrm{gulma} / \mathrm{m}^{2}$. Bila asumsi terpenuhi data dianalisis ragam dan dilanjutkan dengan uji beda nyata terkecil (BNT) pada taraf $5 \%$. Hasil penelitian menunjukkan bahwa daya tekan gulma Rottboelia exaltata terhadap panjang umbi pada umur 12 MST lebih tinggi dibandingkan dengan gulma Asystasia gangetica dan Cyperus rotundus, kerapatan 10 sampai 80 gulma $/ \mathrm{m}^{2}$ dapat menekan panjang umbi pada umur 12 MST dan antar jenis dan kerapatan gulma terjadi interaksi dalam mempengaruhi jumlah daun, diameter batang, tinggi tanaman, jumlah umbi dan produksi umbi pada umur 12 MST. Daya tekan gulma Rottboelia exaltata lebih tinggi dibandingkan dengan Asystasia gangetica dan Cyperus rotundus.
\end{abstract}

Kata kunci: gulma, kompetisi, ubikayu.

\section{PENDAHULUAN}

Di Indonesia, ubikayu merupakan makanan pokok yang menempati urutan ketiga setelah padi dan jagung. Pemanfaatan ubikayu, selain sebagai bahan pangan banyak pula digunakan sebagai bahan baku industri seperti industri tapioka, industri kertas, industri bahan bakar nabati (BBN), dan bioetanol. Menurut Badan Pusat Statistik (2015), produksi ubikayu di Indonesia tahun 2014 sebesar 23,44 juta ton. Produksi ini mengalami penurunan dibandingkan tahun 2013 sebanyak 0,50 juta ton.

Menurunnya produksi ubikayu disebabkan oleh beberapa faktor, diantaranya penggunaan klon yang belum unggul, pengusaan teknologi budidaya masih rendah, keberadaan hama, penyakit dan gulma serta harga jual yang rendah (Kurniani, 2009). Sehingga perlu adanya usaha untuk meningkatkan produksi ubikayu antara lain dengan menggunakan klon unggul, meningkatkan kualitas sumber daya manusia, dan memperbaiki teknik budidaya tanaman. Salah satu tujuan dari teknik budidaya yang tepat adalah untuk menekan persaingan antara tanaman dan gulma. Menurut Widaryanto dkk (2012), gulma ialah tumbuhan yang keberadaannya merugikan tanaman budidaya, persaingan gulma pada awal pertumbuhan akan mengurangi kuantitas hasil panen. Di daerah Pagak, gulma di sekitar tanaman ubi kayu dapat menurunkan hasil sampai $40 \%$ terutama bila terjadi pada awal pertumbuhan (Moenandir, 2010).

Sifat gulma yang berbeda - beda menentukan besarnya persaingan antar gulma dan tanaman begitupula dengan tingkat kerapatan gulma. Pada tingkat kerapatan yang rendah, persaingan antar gulma dan tanaman masih rendah sehingga kehilangan hasil belum terlihat, sedangkan tingkat kerapatan yang tinggi melebihi ambang kerusakan tanaman, menyebabkan hasil tanaman menurun (Sembodo, 2010).

Penelitian ini bertujuan untuk mengetahui pengaruh jenis gulma terhadap pertumbuhan awal tanaman ubikayu, pengaruh kerapatan gulma terhadap pertumbuhan awal tanaman ubikayu, dan pengaruh interaksi antara jenis dan kerapatan gulma terhadap pertumbuhan awal tanaman ubikayu.

\section{BAHAN DAN METODE}

Penelitian ini dilaksanakan di Lampung Selatan dan Laboratorium Gulma Universitas Lampung mulai bulan Maret - Juni 2015. Bahan dan alat yang digunakan 
yaitu stek ubikayu varietas UJ-5, 3 jenis gulma Asystasia gangetica, Cyperus rotundus, Rottboelia exaltata, meteran, jangka sorong, dan timbangan. Perlakuan disusun secara faktorial dalam Rancangan Petak Berjalur dengan 3 kali ulangan. Faktor pertama adalah 3 jenis gulma dan faktor kedua adalah kerapatan $0,10,20,40$, dan $80 \mathrm{gulma} / \mathrm{m}^{2}$. Lahan penelitian diolah dengan cara dicangkul, kemudian dibuat 45 petak masing-masing petak berukuran 2,4 x 1,5 m dengan jarak antarpetak 0,5 $\mathrm{m}$. Penanaman stek ubikayu dengan panjang stek $20 \mathrm{~cm}$ dilakukan setelah 1 minggu transplanting gulma ke petak perlakuan. Penanaman stek sebanyak 9 stek setiap petak perlakuan dengan jarak tanam $80 \mathrm{~cm}$ x $50 \mathrm{~cm}$. Pada kerapatan 10,20,40, dan 80 gulma/ $\mathrm{m}^{2}$ jarak tanam yang digunakan berturut - turut yaitu $25 \mathrm{~cm} \mathrm{x} 40 \mathrm{~cm}, 25 \mathrm{~cm}$ x $20 \mathrm{~cm}, 25 \mathrm{~cm}$ x $10 \mathrm{~cm}$, dan $12,5 \mathrm{~cm} \times 10 \mathrm{~cm}$. Ubi kayu dipupuk dengan dosis Urea $200 \mathrm{~kg} / \mathrm{Ha}$, SP-36 dosis $100 \mathrm{~kg} / \mathrm{Ha}$ dan $\mathrm{KCl}$ dosis $100 \mathrm{~kg} / \mathrm{Ha}$. Pemupukan dilakukan $2 \mathrm{MST}$ dengan menggunakan setengah dosis urea, seluruh dosis SP-36 dan dosis $\mathrm{KCl}$ dengan cara ditugal diberikan sisa pupuk urea pada 2 BST (bulan setelah tanam). Variabel pengamatan dalam penelitian ini yaitu pertumbuhan gulma dan pertumbuhan tanaman. Pertumbuhan gulma meliputi bobot kering gulma, sedangkan pertumbuhan tanaman meliputi tinggi tanaman, diameter tanaman, jumlah daun, panjang umbi, serta produksi umbi/petak pada umur 12 MST. Homogenisitas diuji dengan uji Bartlett dan uji aditivitas data diuji dengan uji Tukey. Bila asumsi terpenuhi, data dianalisis ragam dan dilanjutkan dengan uji BNT pada taraf 5\%.

\section{HASIL DAN PEMBAHASAN}

Bobot kering gulma dipengaruhi oleh interaksi antara jenis dan tingkat kerapatan gulma (Tabel 1). Bobot kering gulma Rottboelia exaltata lebih tinggi dibandingkan dengan Asystasia gangetica dan Cyperus rotundus pada kerapatan 10,20,40, dan $80 \mathrm{gulma} / \mathrm{m}^{2}$. Pertumbuhan gulma dipengaruhi oleh kondisi lingkungan yaitu oleh penyinaran dan naungan. Rendahnya bobot kering total gulma antara lain juga diakibatkan terbatasnya ruang tumbuh gulma dan terbatasnya cahaya matahari yang dapat dimanfaatkan gulma untuk berfotosintesis akibat ternaungi oleh kanopi ubikayu begitu sebaliknya (Hardiman dkk., 2013).

Hal ini didukung oleh Le Roy G. Holm dkk. (1988) dalam Suryaningsih dkk. (2011) yang menyatakan bahwa famili Poacea (golongan rumput), termasuk gulma Rottboelia exaltata merupakan gulma yang mempunyai kemampuan adaptasi yang tinggi, dapat tumbuh pada kondisi ekstrim karena termasuk gulma ganas, penyebarannya luas, akar yang kuat dan berkembangbiak dengan biji. Akibatnya gulma tersebut dapat mengusai ruang tempat tumbuh dan unggul dalam persaingan dengan tanaman pokok.

Bobot kering gulma Asystasia gangetica pada kerapatan 40 dan $80 \mathrm{gulma} / \mathrm{m}^{2}$ tidak berbeda tetapi lebih besar dibandingkan dengan kerapatan 10 dan 20 gulma/ $\mathrm{m}^{2}$, begitupula dengan bobot kering pada gulma Cyperus rotundus dan Rottboelia exaltata. Hal ini didukung oleh Hasanuddin dkk. (2012) yang menyatakan bahwa tingkat kerapatan gulma yang tinggi akan berkurang

Tabel 1. Pengaruh interaksi antara jenis dan kerapatan gulma terhadap bobot kering gulma $\left(\mathrm{g} / 0,25 \mathrm{~m}^{2}\right)$

\begin{tabular}{|c|c|c|c|c|c|c|c|}
\hline \multirow{3}{*}{$\begin{array}{l}\text { Kerapatan } \\
\text { Gulma/m² }\end{array}$} & \multicolumn{6}{|c|}{ Bobot Kering Gulma } & \multirow{3}{*}{$\begin{array}{c}\mathrm{BNT} \\
5 \%\end{array}$} \\
\hline & \multicolumn{3}{|c|}{ Asli } & \multicolumn{3}{|c|}{ Transformasi $(\sqrt{ }(x+0,5))$} & \\
\hline & $\begin{array}{l}\text { Asystasia } \\
\text { gangetica }\end{array}$ & $\begin{array}{l}\text { Cyperus } \\
\text { rotundus }\end{array}$ & $\begin{array}{c}\text { Rootboelia } \\
\text { exaltata }\end{array}$ & $\begin{array}{l}\text { Asystasia } \\
\text { gangetica }\end{array}$ & $\begin{array}{l}\text { Cyperus } \\
\text { rotundus }\end{array}$ & $\begin{array}{c}\text { Rootboelia } \\
\text { exaltata }\end{array}$ & \\
\hline 0 & 0,00 & 0,00 & 0,00 & $\begin{array}{c}0,92 \mathrm{~d} \\
\text { (a) }\end{array}$ & $\begin{array}{c}0,92 \mathrm{~d} \\
\text { (a) }\end{array}$ & $\begin{array}{c}0,92 \mathrm{~d} \\
\text { (a) }\end{array}$ & \\
\hline 10 & 7,31 & 13,20 & 18,12 & $\begin{array}{c}1,54 \mathrm{c} \\
\text { (c) }\end{array}$ & $\begin{array}{c}1,59 \mathrm{c} \\
\text { (b) }\end{array}$ & $\begin{array}{c}1,64 \mathrm{c} \\
\text { (a) }\end{array}$ & \\
\hline 20 & 13,34 & 23,97 & 28,47 & $\begin{array}{c}1,62 \mathrm{~b} \\
\text { (b) }\end{array}$ & $\begin{array}{c}1,69 \mathrm{~b} \\
\text { (a) }\end{array}$ & $\begin{array}{c}1,71 \mathrm{~b} \\
\text { (a) }\end{array}$ & 0,02 \\
\hline 40 & 26,20 & 33,87 & 33,83 & $\begin{array}{c}1,71 \mathrm{a} \\
\text { (b) }\end{array}$ & $\begin{array}{c}1,72 \mathrm{a} \\
\text { (b) }\end{array}$ & $\begin{array}{c}1,75 \mathrm{a} \\
\text { (a) }\end{array}$ & \\
\hline 80 & 33,39 & 36,13 & 39,37 & $\begin{array}{c}1,72 \mathrm{a} \\
\text { (b) }\end{array}$ & $\begin{array}{c}1,73 \mathrm{a} \\
\text { (b) }\end{array}$ & $\begin{array}{c}1,76 \mathrm{a} \\
\text { (a) }\end{array}$ & \\
\hline BNT $5 \%$ & & & & & $(0,02)$ & & \\
\hline
\end{tabular}

Keterangan : Angka yang diikuti oleh huruf yang sama tidak berbeda nyata berdasarkan uji BNT pada taraf $5 \%$, dengan tanda kurung (jenis gulma) dan tanpa tanda kurung (kerapatan gulma). 
secara alami seiring bertambahnya waktu karena terjadi persaingan antar tanaman.

Tinggi tanaman dipengaruhi oleh interaksi antara jenis dan tingkat kerapatan gulma (Tabel 2). Tanaman ubikayu yang berkompetisi dengan Cyperus rotundus lebih tinggi dibandingkan dengan Asystasia gangetica dan Rottboelia exaltata pada kerapatan $10 \mathrm{gulma} / \mathrm{m}^{2}$. Pada kerapatan 20 gulma $/ \mathrm{m}^{2}$ tanaman ubikayu yang berkompetisi dengan Asystasia gangetica lebih tinggi dibandingkan dengan Rottboelia exaltata dan Cyperus rotundus. Pada kerapatan 40 dan 80 gulma $/ \mathrm{m}^{2}$ tanaman ubikayu yang berkompetisi dengan Rottboelia exaltata lebih rendah dibandingkan dengan Cyperus rotundus dan Asystasia gangetica namun pada kerapatan yang sama persentase penutupan gulma Cyperus rotundus dan Asystasia gangetica tidak berbeda.

Tinggi tanaman ubikayu yang berkompetisi dengan gulma Asystasia gangetica tidak berbeda pada kerapatan 10 dan 20 gulma/m $/ \mathrm{m}^{2}$ tetapi lebih tinggi dibandingkan dengan kerapatan 40 dan $80 \mathrm{gulma} / \mathrm{m}^{2}$. Tanaman ubikayu yang berkompetisi dengan gulma Cyperus rotundus pada kerapatan $10 \mathrm{gulma} / \mathrm{m}^{2}$ lebih tinggi dibandingkan dengan kerapatan 20, 40, dan 80 gulma/ $\mathrm{m}^{2}$. Tanaman ubikayu yang berkompetisi dengan gulma Rottboelia exaltata pada kerapatan 10 gulma/ $\mathrm{m}^{2}$ lebih tinggi dibandingkan dengan kerapatan 20, 40, dan 80 gulma $/ \mathrm{m}^{2}$. Kompetisi cahaya akan mengendalikan proses fotosintesis tumbuhan. Kompetisi tersebut dipengaruhi oleh faktor - faktor yang mempengaruhi penyerapan cahaya oleh daun seperti bentuk daun, luas tajuk, tinggi tanaman. Oleh karena itu, apabila tanaman tidak mendapatkan cahaya karena ternaungi oleh gulma maka ia tidak mempunyai energi untuk tumbuh, kompetisi gulma dan tanaman (Shooichi, 1977 dalam Mayasari, 2011). Hal ini didukung oleh Bilman (2001) yang menyatakan bahwa kompetisi gulma terhadap cahaya juga bergantung pada laju pertumbuhan gulma serta kerapatannya. Jika kerapatan gulma tinggi dan perkembangannya lebih cepat akan menimbulkan kompetisi yang lebih kompleks.

Jumlah daun dipengaruhi oleh interaksi antara jenis dan tingkat kerapatan gulma (Tabel 2). Daun ubikayu yang berkompetisi dengan gulma Rottboelia exaltata lebih sedikit dibandingkan dengan gulma Asystasia gangetica dan Cyperus rotundus pada kerapatan $10,20,40$, dan $80 \mathrm{gulma} / \mathrm{m}^{2}$, sedangkan pada kerapatan tersebut jumlah daun yang berkompetisi dengan Asystasia gangetica dan Cyperus rotundus terlihat tidak berbeda. Semakin tinggi kompetisi yang terjadi menyebabkan pertumbuhan daun menjadi terhambat. Pertumbuhan daun yang baik akan menyebabkan pertumbuhan dan perkembangan tanaman yang baik pula dan pertumbuhan daun yang baik mampu menyerap cahaya dengan maksimal begitupula sebaliknya (Triyono, 2010).

Pada kerapatan 10, 20, 40, dan 80 gulma/m² jumlah daun ubikayu yang berkompetisi dengan Asystasia gangetica terlihat tidak ada perbedaan begitupula dengan Cyperus rotundus sedangkan jumlah daun yang berkompetisi dengan gulma Rottboelia exaltata terlihat tidak berbeda pada kerapatan 10 dan $20 \mathrm{gulma} / \mathrm{m}^{2}$ begitupula pada kerapatan 20,40 , dan 80

Tabel 2. Pengaruh interaksi pengaruh jenis dan kerapatan gulma pada tinggi tanaman (cm) dan jumlah daun (helai/ tanaman) pada umur 12 MST.

\begin{tabular}{|c|c|c|c|c|c|c|c|c|}
\hline \multirow{2}{*}{$\begin{array}{l}\text { Kerapatan } \\
\text { Gulma/m² }\end{array}$} & \multicolumn{4}{|c|}{ Tinggi Tanaman $(\mathrm{cm})$} & \multicolumn{4}{|c|}{ Jumlah Daun (helai) } \\
\hline & $\begin{array}{l}\text { Asystasia } \\
\text { gangetica }\end{array}$ & $\begin{array}{l}\text { Cyperus } \\
\text { rotundus }\end{array}$ & $\begin{array}{c}\text { Rootboelia } \\
\text { exaltata }\end{array}$ & $\begin{array}{c}\mathrm{BNT} \\
5 \%\end{array}$ & $\begin{array}{l}\text { Asystasia } \\
\text { gangetica }\end{array}$ & $\begin{array}{l}\text { Cyperus } \\
\text { rotundus }\end{array}$ & $\begin{array}{c}\text { Rootboelia } \\
\text { exaltata }\end{array}$ & $\begin{array}{l}\mathrm{BNT} \\
5 \%\end{array}$ \\
\hline 0 & $\begin{array}{c}177,17 \mathrm{a} \\
\text { (b) }\end{array}$ & $\begin{array}{c}177,33 \mathrm{a} \\
\text { (a) }\end{array}$ & $\begin{array}{c}178,25 \mathrm{a} \\
\text { (a) }\end{array}$ & & $\begin{array}{c}38,58 \mathrm{a} \\
\text { (a) }\end{array}$ & $\begin{array}{c}39,25 \mathrm{a} \\
\text { (a) }\end{array}$ & $\begin{array}{c}39,58 \mathrm{a} \\
\text { (a) }\end{array}$ & \\
\hline 10 & $\begin{array}{c}147,58 \mathrm{~b} \\
\text { (b) }\end{array}$ & $\begin{array}{c}158,42 \mathrm{~b} \\
\text { (a) }\end{array}$ & $\begin{array}{c}140,26 \mathrm{~b} \\
\text { (c) }\end{array}$ & & $\begin{array}{c}36,00 \mathrm{ab} \\
\text { (a) }\end{array}$ & $\begin{array}{c}35,58 \text { a } \\
\text { (a) }\end{array}$ & $\begin{array}{l}16,50 \mathrm{~b} \\
\text { (b) }\end{array}$ & \\
\hline 20 & $\begin{array}{c}141,25 \mathrm{~b} \\
\text { (a) }\end{array}$ & $\begin{array}{c}135,17 \mathrm{c} \\
\text { (b) }\end{array}$ & $\begin{array}{c}117,25 \mathrm{c} \\
\text { (c) }\end{array}$ & 6,44 & $\begin{array}{c}31,33 \mathrm{~b} \\
\text { (a) }\end{array}$ & $\begin{array}{c}34,17 \text { a } \\
\text { (a) }\end{array}$ & $\begin{array}{c}22,83 \text { bc } \\
\text { (b) }\end{array}$ & 6,31 \\
\hline 40 & $\begin{array}{c}120,50 \mathrm{c} \\
\text { (a) }\end{array}$ & $\begin{array}{c}119,42 \mathrm{~d} \\
\text { (a) }\end{array}$ & $\begin{array}{c}98,83 \mathrm{~d} \\
\text { (b) }\end{array}$ & & $\begin{array}{c}30,50 \mathrm{~b} \\
\text { (a) }\end{array}$ & $\begin{array}{c}33,25 \text { a } \\
\text { (a) }\end{array}$ & $\begin{array}{c}18,00 \mathrm{c} \\
\text { (b) }\end{array}$ & \\
\hline 80 & $\begin{array}{c}97,33 \mathrm{~d} \\
\text { (a) }\end{array}$ & $\begin{array}{l}101,58 \mathrm{e} \\
\text { (a) }\end{array}$ & $\begin{array}{l}80,08 \text { e } \\
\text { (b) }\end{array}$ & & $\begin{array}{c}29,69 \mathrm{~b} \\
\text { (a) }\end{array}$ & $\begin{array}{c}32,94 \text { a } \\
\text { (a) }\end{array}$ & $\begin{array}{c}15,58 \mathrm{c} \\
\text { (b) }\end{array}$ & \\
\hline BNT $5 \%$ & \multicolumn{4}{|c|}{$(5,68)$} & \multicolumn{4}{|c|}{$(5,72)$} \\
\hline
\end{tabular}

Keterangan : Angka yang diikuti oleh huruf yang sama tidak berbeda nyata berdasarkan uji BNT pada taraf $5 \%$, dengan tanda kurung (jenis gulma) dan tanpa tanda kurung (kerapatan gulma). 
gulma $/ \mathrm{m}^{2}$. Semakin tinggi kerapatan gulma maka semakin tinggi kompetisi yang terjadi dan berpengaruh pada pertumbuhan daun akibat terbatasnya sarana tumbuh yang tersedia terutama cahaya.

Daun merupakan organ tanaman yang utama dalam menyerap radiasi matahari. Penyerapan cahaya yang maksimal akan mempengaruhi pertumbuhan dan produksi tanaman karena cahaya yang maksimal akan meningkatkan kandungan klorofil begitupula sebaliknya (Pamuji dan Saleh, 2010). Semakin banyak jumlah daun yang dihasilkan maka proses fotosintesis akan berjalan dengan baik dan akan menghasilkan proses fotosintat serta energi yang lebih besar untuk pertumbuhan dan perkembangan tanaman (Hardiman dkk., 2013).

Diameter batang ubikayu dipengaruhi oleh interaksi antara jenis dan tingkat kerapatan gulma (Tabel 3). Diameter batang ubikayu yang berkompetisi dengan gulma Rottboelia exaltata lebih kecil dibandingkan dengan gulma Asystasia gangetica dan Cyperus rotundus pada kerapatan 10, 20, 40, dan $80 \mathrm{gulma} / \mathrm{m}^{2}$, sedangkan pada kerapatan yang sama diameter batang yang berkompetisi dengan Asystasia gangetica dan Cyperus rotundus terlihat tidak berbeda. Pada kerapatan 10,20,40, dan 80 gulma/m² diameter ubikayu yang berkompetisi dengan Asystasia gangetica tidak ada perbedaan, begitupula yang berkompetisi dengan Cyperus rotundus. Diameter batang yang berkompetisi dengan Rottboelia exaltata terlihat tidak berbeda pada kerapatan 10, 20, 40, dan 80 gulma/m² tetapi lebih kecil dibandingkan kontrol. Jenis dan kerapatan gulma mempengaruhi diameter tanaman ubikayu akibat persaingan. Kompetisi yang terjadi mempengaruhi intensitas cahaya yang diserap oleh tumbuhan ternaungi sehingga menjadi kecil atau sebagian kecil dari intensitas cahaya keseluruhan (Moenandir, 2010).

Panjang umbi tidak dipengaruhi oleh interaksi antara jenis dan tingkat kerapatan gulma (Tabel 4). Umbi ubikayu yang berkompetisi dengan Rottboelia exaltata lebih pendek dibandingkan dengan Asystasia gangetica dan Cyperus rotundus, sedangkan umbi yang berkompetisi dengan Asystasia gangetica dan Cyperus rotundus panjang umbi tidak berbeda. Umbi ubikayu pada kerapatan 80 gulma $/ \mathrm{m}^{2}$ lebih pendek dibandingkan dengan kerapatan 10, 20, dan 40 gulma/m². Semakin tinggi kerapatan maka semakin menurunkan jumlah umbi dan ukuran umbi ubikayu berupa panjang umbi (Syam dkk., 2013). Hal ini didukung oleh Pasau, dkk. (2008) yang menyatakan bahwa kerpatan gulma yang tinggi akan diikuti oleh tingginya agresifitas gulma terhadap tanaman akibatnya akan menurunkan hasil tanaman yang tinggi pula.

Bobot umbi/petak dipengaruhi oleh interaksi antara jenis dan tingkat kerapatan gulma (Tabel 3). Umbi ubikayu yang berkompetisi dengan Rottboelia exaltata memiliki bobot umbi yang lebih sedikit dibandingkan dengan Asystasia gangetica dan Cyperus rotundus pada kerapatan 10, 20, 40 dan $80 \mathrm{gulma} / \mathrm{m}^{2}$. Namun, pada kerapatan gulma, setiap tingkat kerapatan ketiga jenis gulma mengalami penurunan produksi dibandingkan dengan kontrol. Semakin tinggi tingkat kerapatan gulma maka semakin tinggi kehilangan hasil ubikayu akibat persaingan tersebut. Pada kerapatan yang tinggi, akan

Tabel 3. Interaksi pengaruh jenis dan kerapatan gulma pada diameter tanaman $(\mathrm{cm})$ dan bobot umbi/ petak $(\mathrm{kg} / 3,6$ $\mathrm{m}^{2}$ ) umur 12 MST.

\begin{tabular}{|c|c|c|c|c|c|c|c|c|}
\hline \multirow{2}{*}{$\begin{array}{l}\text { Kerapatan } \\
\text { Gulma/m² }\end{array}$} & \multicolumn{4}{|c|}{ Diameter tanaman $(\mathrm{cm})$} & \multicolumn{4}{|c|}{ Bobot umbi/petak $\left(\mathrm{kg} / 3,6 \mathrm{~m}^{2}\right)$} \\
\hline & $\begin{array}{l}\text { Asystasia } \\
\text { gangetica }\end{array}$ & $\begin{array}{l}\text { Cyperus } \\
\text { rotundus }\end{array}$ & $\begin{array}{c}\text { Rootboelia } \\
\text { exaltata } \\
\end{array}$ & $\begin{array}{c}\mathrm{BNT} \\
5 \% \\
\end{array}$ & $\begin{array}{l}\text { Asystasia } \\
\text { gangetica }\end{array}$ & $\begin{array}{l}\text { Cyperus } \\
\text { rotundus }\end{array}$ & $\begin{array}{c}\text { Rootboelia } \\
\text { exaltata } \\
\end{array}$ & $\begin{array}{c}\text { BNT } \\
5 \% \\
\end{array}$ \\
\hline 0 & $\begin{array}{c}1,82 \mathrm{a} \\
\text { (a) }\end{array}$ & $\begin{array}{l}1,93 \mathrm{a} \\
\text { (a) }\end{array}$ & $\begin{array}{c}1,92 \mathrm{a} \\
\text { (a) }\end{array}$ & & $\begin{array}{c}3,94 \mathrm{a} \\
\text { (a) }\end{array}$ & $\begin{array}{c}3,93 \mathrm{a} \\
\text { (a) }\end{array}$ & $\begin{array}{c}3,95 \mathrm{a} \\
\text { (a) }\end{array}$ & \\
\hline 10 & $\begin{array}{c}1,67 \mathrm{a} \\
\text { (a) }\end{array}$ & $\begin{array}{l}1,78 \mathrm{a} \\
\text { (a) }\end{array}$ & $\begin{array}{l}0,97 \mathrm{~b} \\
\text { (b) }\end{array}$ & & $\begin{array}{c}3,00 \mathrm{~b} \\
\text { (a) }\end{array}$ & $\begin{array}{c}2,88 \mathrm{~b} \\
\text { (b) }\end{array}$ & $\begin{array}{c}0,53 \mathrm{~b} \\
\text { (c) }\end{array}$ & \\
\hline 20 & $\begin{array}{c}1,59 \mathrm{a} \\
\text { (a) }\end{array}$ & $\begin{array}{c}1,49 \mathrm{a} \\
\text { (a) }\end{array}$ & $\begin{array}{c}0,80 \mathrm{~b} \\
\text { (b) }\end{array}$ & 0,52 & $\begin{array}{c}2,89 \mathrm{c} \\
\text { (a) }\end{array}$ & $\begin{array}{c}2,78 \mathrm{c} \\
\text { (b) }\end{array}$ & $\begin{array}{c}0,46 \mathrm{c} \\
\text { (c) }\end{array}$ & 0,06 \\
\hline 40 & $\begin{array}{c}1,35 \mathrm{a} \\
\text { (a) }\end{array}$ & $\begin{array}{c}1,46 \mathrm{a} \\
\text { (a) }\end{array}$ & $\begin{array}{c}0,79 \mathrm{~b} \\
\text { (b) }\end{array}$ & & $\begin{array}{l}2,42 \mathrm{~d} \\
\text { (b) }\end{array}$ & $\begin{array}{c}2,53 \mathrm{~d} \\
\text { (a) }\end{array}$ & $\begin{array}{c}0,35 \mathrm{~d} \\
\text { (c) }\end{array}$ & \\
\hline 80 & $\begin{array}{c}1,32 \mathrm{a} \\
\text { (a) }\end{array}$ & $\begin{array}{c}1,43 \mathrm{a} \\
\text { (a) }\end{array}$ & $\begin{array}{c}0,68 \mathrm{~b} \\
\text { (b) }\end{array}$ & & $\begin{array}{c}1,74 \mathrm{e} \\
\text { (b) }\end{array}$ & $\begin{array}{c}1,88 \mathrm{e} \\
\text { (a) }\end{array}$ & $\begin{array}{c}0,28 \mathrm{e} \\
\text { (c) }\end{array}$ & \\
\hline BNT $5 \%$ & \multicolumn{4}{|c|}{$(0,28)$} & \multicolumn{4}{|c|}{$(0,04)$} \\
\hline
\end{tabular}

Keterangan : Angka yang diikuti oleh huruf yang sama tidak berbeda nyata berdasarkan uji BNT pada taraf $5 \%$, dengan tanda kurung (jenis gulma) dan tanpa tanda kurung (kerapatan gulma). 
Tabel 4. Pengaruh jenis dan kerapatan gulma pada panjang umbi $(\mathrm{cm})$ umur $12 \mathrm{MST}$.

\begin{tabular}{lc}
\hline \multicolumn{1}{c}{ Perlakuan } & Panjang umbi \\
\hline Jenis Gulma : & \\
Asystasia gangetica & $25,80 \mathrm{a}$ \\
Cyperus rotundus & $25,10 \mathrm{a}$ \\
Rootboelia exaltata & $21,04 \mathrm{~b}$ \\
\hline BNT 5\% & 1,09 \\
\hline Kerapatan gulma $/ \mathrm{m}^{2}:$ & \\
0 & $25,75 \mathrm{a}$ \\
10 & $24,61 \mathrm{ab}$ \\
20 & $23,59 \mathrm{~b}$ \\
40 & $23,11 \mathrm{~b}$ \\
80 & $21,82 \mathrm{c}$ \\
\hline BNT 5\% & 1,40
\end{tabular}

BNT $5 \%$ 1,40

Keterangan : Angka yang diikuti oleh huruf yang sama tidak berbeda nyata berdasarkan uji BNT pada taraf $5 \%$

menurunkan hasil ubikayu akibat persaingan dalam memperoleh hara air dan cahaya matahari (Silaban, 1994 dalam Safitri, 2010). Kehilangan hasil tersebut berkaitan dengan bentuk morfologi gulma dan tanaman itu sendiri serta besarnya kompetisi tergantung pada lamanya kompetisi dan daya kompetisi antara tanaman dan gulma (Zimdahl, 1980 dalam Widayat, 2002).

Pada kerapatan 10 sampai 80 gulma $/ \mathrm{m}^{2}$, tinggi , jumlah daun, diameter batang dan bobot umbi/petak yang berkompetisi dengan gulma Rottboelia exaltata lebih rendah dibandingkan dengan Cyperus rotundus dan Asystasia gangetica. Pengamatan ini sejalan dengan data bobot kering gulma Rottboelia exaltata yang lebih tinggi dibandingkan dengan Cyperus rotundus dan Asystasia gangetica. Oleh karena itu, adanya gulma Rottboelia exaltata di areal tanaman ubikayu perlu dilakukan pengendalian terutama pada awal pertumbuhan karena mengakibatkan pertumbuhan tanaman ubikayu menjadi terhambat dan bobot umbi/ petak $\left(3,6 \mathrm{~m}^{2}\right)$ menurun pada umur 3 bulan setelah tanam (BST).

\section{KESIMPULAN}

Penelitian ini dapat disimpulkan bahwa daya tekan gulma Rottboelia exaltata terhadap panjang umbi umur 12 MST lebih tinggi dibandingkan dengan Asystasia gangetica dan Cyperus rotundus. Kerapatan 10 sampai $80 \mathrm{gulma} / \mathrm{m}^{2}$ dapat menekan panjang umbi pada umur 12 MST. Antar jenis dan kerapatan gulma terjadi interaksi dalam mempengaruhi jumlah daun, diameter batang, tinggi tanaman, dan bobot umbi/petak pada umur
12 MST. Daya tekan gulma Rottboelia exaltata lebih tinggi dibandingkan dengan Asystasia gangetica dan Cyperus rotundus.

\section{DAFTAR PUSTAKA}

Badan Pusat Statistik. 2015. Luas panen-ProduktivitasProduksi Tanaman Ubikayu. Tersedia: http:/ www.bps.go.id, [28 Agustus 2015].

Bilman. W.S. 2001. Jurnal analisis pertumbuhan tanaman jagung manis (Zea mays saccharata Sturt), pergeseran komposisi gulma pada beberapa jarak tanam. Ilmu- Ilmu Pertanian Indonesia. 3(1): 25-30.

Hardiman, T., T. Islami., dan H.T. Sebayang. 2013. Pengaruh waktu penyiangan gulma pada sistem tanam tumpangsari kacang tanah (Arachis hypogaea L.) dengan bbikayu (Manihot esculenta Crantz). Produksi Tanaman Pangan. 2(2): 114-116.

Hasanuddin, G. Erida, dan Safmanela. 2012. Pengaruh persaingan gulma Sinedrella nodiflora L. pada berbagai densitas terhadap pertumbuhan dan hasil kedelai. Agrista. 16(3): 146 -152.

Kurniani. 2009. Efikasi Herbisida Pratumbuh Pendimethalin dan Kombinasinya dengan Diuron dan Metribuzin terhadap Gulma pada Budidaya Ubikayu (Manihot esculenta Crantz). Skripsi. Universitas Lampung. Lampung. $49 \mathrm{hlm}$

Mayasari, Y. 2011. Kompetisi Beberapa Jenis dan Populasi Gulma terhadap Pertumbuhan dan Produksi Tanaman Padi Gogo (Oryza sativa L.) Varietas Cigeulis. Skripsi. Universitas Lampung. Lampung. 96 hal.

Moenandir, J. 2010. Ilmu Gulma. Universitas Brawijaya Press. Malang. $162 \mathrm{hlm}$.

Pamuji, S., dan B. Saleh. 2010. Pengaruh intensitas naungan buatan dan dosis pupuk $\mathrm{K}$ terhadap pertumbuhan dan hasil jahe gajah. Akta Agrosia. 13(1): 62- 69 .

Pasau, P., P. Yudono, dan A. Syukur. 2008. Pergeseran kompetisi gulma pada perbedaan proporsi populasi jagung dan kacang tanah dalam tumpangsari pada Regosol Sleman. Ilmu Pertanian. 16(2): 60-78.

Safitri, R. 2010. Pengaruh jarak tanam dan dosis pupuk kandang ayam terhadap pertumbuhan dan hasil tanaman sorgum manis (Sorghum Bicolor L.). Tanaman Pangan. 3(2): 107 -119. 
Sembodo, D. R. J. 2010. Gulma dan Pengelolaannya. Graha Ilmu. Yogyakarta. $168 \mathrm{hlm}$.

Suryaningsih, M. Jono, A.A.K. Darmadi. 2001. Inventarisasi gulma pada tanaman jagung (Zea mays) di sawah Kelurahan Padang Galak, Denpasar Timur, Kodya Denpasar, Provinsi Bali. Simbiosisis. 1(1): 1-8.

Syam, Z., Yenni, dan Khainur. 2013. Pengaruh kerapatan gulma siamih (Ageratum conyzoides L.) terhadap tanaman cabai keriting (Capsicum annum L.). Prosiding Semirata FMIPA Unila. 505-510 hlm.
Triyono, K. 2010. Pengaruh dosis glifosat dan jarak tanam terhadap pertumbuhan gulma dan hasil Jagung (Zea mays). Jerami. 3(2): 107-119.

Widayat, D. 2002. Kemampuan berkompetisi kedelai (Glycine Max), kacang tanah (A. Hypogea), dan kacang hijau (V. Radiata) terhadap Teki ( $C$. rotundus). Bionatura. 4(2): 118-128.

Widaryanto, E., A.N. Sugiarto, dan R. Ebtan. 2014. Ketahanan beberapa varietas jagung manis (Zea mays saccharata $S$.) terhadap populasi gulma Teki (C. rotundus). Produksi Tanaman. 16(1): 471477. 